\title{
特別講演
}

\section{FROM ANIMALS TO MAN : A SPECIAL PROBLEM IN CLINICAL PHARMACOLOGY}

\author{
Leon I. Goldberg, Ph. D., M.D.* \\ Professor of Medicine (Clinical Pharmacology) and Pharmacology \\ Clinical Pharmacology Program., Emory University \\ School of Medicine, Atlanta, Georgia
}

There are two distinct problems a clinical pharmacologist must solve in the initial trials of a new drug in man. First, he must review the extensive animal data which has been accumulated and decide whether sufficient work has been done to justify administering the drug to man. Second, he must design and execute the human studies. I will discuss the problems encountered in both areas and will then tell you why $I$ think a well-trained clinical pharmacologist is especially needed in Phase I studies.

Fig. 1

\begin{tabular}{|l|}
\hline \multicolumn{2}{|c|}{ PROBLEMS IN ANIMAL STUDIES } \\
1.
\end{tabular}

Unfortunately, despite extensive research and refinement in methodology, there is still considerable debate concerning the relevance of specific animal studies. First, there is the difficulty concerning the most appropriate species. It is not possible to predict which (if anv !) animal will respond to a drug in the same way as man. Thus, most pre-clinical evaluations include investigations in at least three species: a rodent, non-rodent, and primate.

The second unanswered question is whether the types of studies conducted are helpful in planning clinical investigations. The most complete data is concerned with acute and chronic toxicity studies utilizing large doses of the drugs. Data is often presented including possible interactions of the new compound with other drugs. The pharmacological information usually contains the results of screening the compound in a number of standard preparations, but there is often too little information concerning mechanisms of action and metabolism.

* Dr. Goldberg is at present Visiting Professor, Kyoto University School of Medicine, Department of Pharmacology, Kyoto, Japan. (Supportéd in Part by U. S. Public Health Service Grant GM-14270) 
Both of these evaluations can provide vital information for the human studies.

The third problem is to determine how long the new drug should be given to animals before it is administered to a single human being. Most scientists agree that a few months' administration is all that is required. However, one investigator has demanded that no drug be given to man until at least two years' administration to animals has elapsed in order to rule out carcinogenesis. A strong argument against this viewpoint is that tumors in animals may have no relevance in man, especially if the animals studied metabolize the drug differently than man.

We also must remember that very useful drugs, such as isoniazid, can be shown to induce tumors under certain experimental conditions.

My primary area is cardiovascular and I would now like to make some specific comments concerning animal studies of a new anti-hypertensive compound.

Fig. 2

\begin{tabular}{|l|}
\hline \multicolumn{2}{|c|}{ ANTI-HYPERTENSIVE AGENTS } \\
\cline { 2 - 2 } TOXICITY : EFFECTS OF LARGE DOSE \\
1) REVERSIBLE-NE?; ANGIOTENSIN ETC. \\
2) HEART (RATE, CF) ; ARRHYTHMIAS \\
3) POSTURAL EFFECTS \\
4) CONDITION OF ANIMAL- \\
UNANESTHETIZED \\
5) CNS, LIVER, GI, ETC. \\
6) ABSORPTION, EXCRETION, \\
METABOLISM (? SPECIES) \\
\hline
\end{tabular}

I particularly ask the following questions regarding toxicology :

1. Are the effects of a large dose reversible by norepinephrine, angiotensin or other drugs? This information is extremely important in the case of an antihypertensive agent since one must know whether an exaggerated response can be reversed.

2. What are the effects on heart rate, cardiac contractile force, and electrocardiogram? If bradycardia, a negative inotropic action, or arrhythmias are observed, I want to know the best way to antagonize them.

3. Does the drug affect postural reflexes in animals or is the hypotension unrelated to posture?

4. What were the conditions of the animals? It is particularly important to know whether there was marked variability among the species.

5. Does the drug produce CNS, liver or other organ pathology?

6. How was the drug absorbed, excreted and metabolized? Were there marked species variations?

Then I would examine the pharmacological data for mechanisms of action. I would like to know the relative efficacy in the various animal models and then the proposed sites 
Fig. 3

\begin{tabular}{|c|}
$\frac{\text { ANTI-HYPERTENSIVE AGENTS }}{\text { PHARMACOLOGICAL DATA }}$ \\
SPECIES-EXPERIMENTAL MODELS \\
MECHANISM OF ACTION \\
CENTRAL-CAROTID SINUS-GANGLION \\
POSTGANGLIONIC SYMPATHETIC NERVE- \\
RECEPTOR-SMOOTH MUSCLE-OTHER \\
\hline
\end{tabular}

of action. In the case of antihypertensive compounds, this should include examinations of the central nervous system, carotid sinus, autonomic ganglia, the postganglionic sympathetic nerve, the autonomic receptors, and the smooth muscle of blood vessels. If the drug acts by an entirely new mechanism, this should be clearly established.

With this brief discussion of animal studies, I will now discuss human investigations. On September 30, 1972, I presented a lecture to a committee of the Japan Science Foundation and the Pharmaceutical Association of Japan in which I emphasized the ethical problems involved in clinical research. I will not repeat those comments now, but want to emphasize that scientific and ethical issues usually cannot be separated. For example, an ethical issue may be involved in a discussion of children as subjects for research. Science, however, is necessary in order to estimate whether such a child will benefit more than he will risk by being given a new drug. The risk benefit ratio must always be considered in any ethical discussion.

Fig. 4

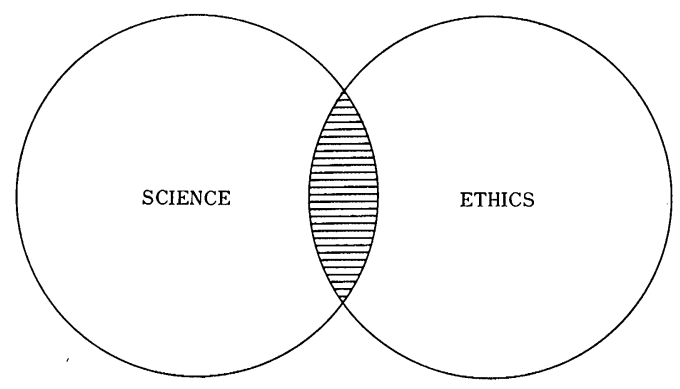

With respect to planning human studies, there are three very difficult decisions which must be made. First, should the volunteer be a normal subject or a patient? There are good arguments for both viewpoints. The metabolism and laboratory data would not be altered by disease processes, and subjective and objective signs of toxicity would not be mistaken for symptoms of the disease in the normal subject. On the other hand, it would be extremely useful to know how a sick person metabolized the drug. First administration of a drug to a sick person may also provide preliminary data on efficacy. It is, of course, more justifiable on ethical grounds to administer a new drug to patients than to normal 
Fig. 7

\begin{tabular}{l}
\hline CONCEPT I \\
PREFER FEWER ANIMALS WITH PERTINENT \\
DATA THAN MASS SCREEN WITH FEWER \\
MEASUREMETS. EX. IF DRUG IS USED \\
BY IV INFUSION, CARDIOVASCULAR \\
MEASUREMENTS WITH IV INFUSION WORTH \\
MORE THAN LD50 BY SINGLE INJECTION
\end{tabular}

My second concept is that a new drug should be investigated in man as soon as possible. I prefer to start with a patient with disease because of ethical issues, but I am not rigid on this point. I want to obtain metabolic studies as soon as possible in man so that additional animal studies can be conducted in the most appropriate species.

Fig. 8

\begin{tabular}{|l|}
$\frac{\text { CONCEPT II }}{\text { INVESTIGATE DRUG IN MAN AS SOON AS }}$ \\
POSSIBLE. PREFER TO STUDY PATIENT \\
WITH DISEASE INITIALLY. BACK TO \\
ANIMALS TO ANSWER QUESTIONS \\
\hline
\end{tabular}

Thus, although the title of this address is From Animals to Man, it is equally important to move in the opposite direction, from man to animal. Dr. Gerhard Zbinden, a noted Swiss pharmacologist and pathologist, has likened the early trials of a new drug to a game of ping-pong. This alternation between animals and man has been very important in the work my colleagues and $I$ have carried out on dopamine, for we have moved from animals to man and back more than ten times. As an example, when we discovered that dopamine caused renal vasodilation in man, it was necessary to return to animals to investigate the mechanisms responsible for the dilating effects.

Fig. 9

$$
\begin{aligned}
& \stackrel{\text { "PING-PONG } "}{ } \\
& \text { ANIMAL } \longrightarrow \text { MAN } \\
& \text { ANIMAL } \longleftarrow \text { MAN }
\end{aligned}
$$

Finally, I feel that entirely too many studies are carried out in animals to demonstrate obvious interactions. When I ask my friends in the pharmaceutical industry why they perform such apparently irrelevant studies, the usual response is that they are afraid the Food \& Drug Administration will require such investigations and it is best to do them early rather than delay clinical trials at a later date. Hopefully, we will be able to avoid the use 
of illogical studies in the future by improved communications between government and industry.

Fig. 10

$\frac{\text { CONCEPT III }}{\text { WASTE OF TIME TO DO STUDIES OF ALL }}$
POSSIBLE INTERACTIONS IN ANIMALS.
MECHANISM OF ACTION AND TOXICITY
DATA SHOULD BE GUIDE. EX. IF
DRUG IS A THIAZIDE DIURETIC AND
$\downarrow \mathrm{K}^{+}$-OBVIOUS PROBLEM WITH
DIGITALIS.

I feel very strongly that we must continue to investigate new methods which will permit us to obtain more data from normal subjects and patients without danger or discomfort. The ethical pressures will not relax. Indeed, they will almost certainly become more intense. Thus, we must develop techniques which will provide physiological information without requiring invasion of the body (so-called "non-invasive" techniques). We must also improve chemical methodology to reduce the need for radioactive isotopes. New developments in gas-chromotography and mass spectroscopy are steps in the right direction.

Fig. 11

RESEARCH NEEDED
NON-INVASIVE PHYSIOLOGICAL MEASUREMENTS
NON-RADIOACTIVE METHODS FOR DRUGS AND
METABOLITES

I have purposefully emphasized the necessity of having a scientist trained in pharmacology involved in phase I studies. There are two ways to accomplish this goal. One is to have direct communication between the basic scientists and the clinical specialists and the other is to have Phase I studies conducted by clinical pharmacologists trained in pharmacology and clinical investigation. Such an individual should be acceptable by both his basic scientist and clinical colleagues and should therefore greatly facilitate communications.

Fig. 12

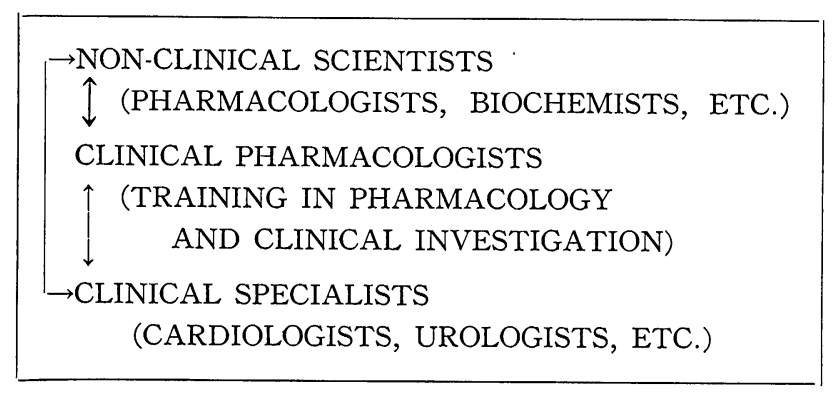


The combination of a clinical and a basic scientist is not rare. However, until recently most such individuals were not interested in pharmacology. At present, both the government and the pharmaceutical industry in the United States are providing funds for the training of clinical pharmacologists and their numbers are slowly increasing. As a pioneering. example, the Burroughs Wellcome Fund has provided large sums of money to 22 medical schools to support the development of clinical pharmacology.

The alternate way to reach the goal is to have two or more different scientists work together - the clinician and the basic scientist. Obviously, until more clinical pharmacologists are trained, most new drug studies must be carried out by such individuals.

Finally, I want to tell you about another development which has taken place in the United States in recent years. Both the U.S. Government through the National Institutes of Health and the pharmaceutical industry have been instrumental in providing funds for large clinical pharmacology programs where many different scientists can work together to approve the safety and efficacy of drugs. I direct such a unit at Emory University School of Medicine and there are about ten more now operating in other academic centers. In our program, we have the ability to synthesize new compounds, study them pharmacologically in animals and then investigate them in the various phases of human evaluations. With such a program, it is possible to have collaborative research at all levels so that the project may initiate in man or in animals and indeed sometimes from a chance laboratory or clinical observation.

Fig. 13

\begin{tabular}{|lll|} 
& \multicolumn{1}{c}{ CLINICAL PHARMACOLOGY PROGRAM } \\
\cline { 2 - 3 } BASIC & $\longleftarrow$ & CLINICAL \\
SYNTHESIS & PHARMACOKINETICS & \multicolumn{1}{c|}{ PHASE I, II, III } \\
IN-VITRO & MECHANISMS OF ACTION & DRUG TRIALS \\
ANIMALS & CHANCE OBSERVATIONS & NEW USES \\
\hline
\end{tabular}

I have only been in Japan two months, but already I have detected enthusiasm on the part of both pharmacologists and clinicians for increased development of clinical pharmacology. I have also found interest in clinical pharmacology at academic, governmental and industrial levels. I know that your young pharmacologists and clinicians are excellently trained and that many of them desire clinical pharmacology as a career. It seems to me that Japan is ready to take the step and begin supporting the further development of this relatively new discipline. Grants should be provided for young scientists to obtain experience in other countries and support should be provided by goverment and industry to help develop outstanding clinical pharmacology programs in your universities. I hope that I will be able to assist you in achieving these goals. 


\section{Pertinent References}

Goldberg, L. I. : Training Clinical Pharmacologists, A multidisciplinary approach, In Conference on Human Pharmacology. C. W. Murphy and J. M. Parker, Eds. McGill University Press, Montreal, Canada pp. 51-57 (1965).

Clinical Pharmacology: Present Status and Future Development. Science. 152 ; 388-391 (1966).

Goldberg, L. I. : The quest for dual competence, A training program in basic and clinical pharmacology. Proc. III International Pharmacological Meeting. (Sao Paulo, Brazil, 1966) III ; 15-19 (1966).

Creasy, W. M. : Burroughs Wellcome Fund Clinical Pharmacology Award Program. Clin Pharmacol. Therk-Thr. 7 ; 112-116 (1966).

World Health Organization. Clinical Pharmacology: Scope, Organization, Training. World Health Organ. Tech. Rep. Ser. No. 446, 21 p (1970).

National Academy of Science, Report of the Conference on Clinical Pharmacology, December 3-4, 1970, NAS-NRS, Washington, D. C. 20 p (1971).

Goldberg, L. I. : Cardiovascular and Renal Action of Dopamine: Potential Clinical Applications. Pharmacol. Rev. 24 ; 1-29 (1972). 